Score on general health questionnaire related to serum cholesterol concentration in men and women

\begin{tabular}{lcc}
\hline & \multicolumn{2}{c}{$\begin{array}{c}\text { Mean (SD) score on general health } \\
\text { questionnaire }\end{array}$} \\
\cline { 2 - 3 } $\begin{array}{l}\text { Serum } \\
\text { cholesterol } \\
\text { (mmol/ })\end{array}$ & Men & Women \\
\hline$<3 \cdot 2$ & $22 \cdot 27(7 \cdot 00)(n=11)$ & $33.43(19 \cdot 03)(n=7)$ \\
$3 \cdot 2-4 \cdot 2$ & $23.65(10 \cdot 25)(n=71)$ & $21.95(11 \cdot 12)(n=64)$ \\
$>4.2$ & $21.50(8 \cdot 21)(n=40)$ & $25.00(12 \cdot 22)(n=81)$ \\
\hline
\end{tabular}

*Data not available for some patients.

and questionnaire scores, but a subgroup of women-namely, those with low cholesterol concentrations (lowest $5 \%$ of the population)-had significantly poorer mental health as indicated by their questionnaire scores $(p<0.04)$.

Although we found a significant relation only in the women, these data support the suggestion that low cholesterol concentrations may be associated with altered mood. The difference between the sexes was unexpected as the impact of changes induced by diet or drugs has tended to be studied in men, and Lindberg and colleagues found an association between cholesterol and suicide only in men.' Our study, however, was of subjects younger than those in similar studies. Our finding in a relatively small sample, suggests that use of similar psychological methods, rather than the rate of suicide, may allow this topic to advance more rapidly. Our data suggest that particular attention should be directed at those with low cholesterol values.

DAVID BENTON JOYCE FORDY

Department of Psychology,

University College,
Swansea SA2 8PP

1 Lindberg G, Rastam L, Gullberg B, Eklund GA. Low serum cholesterol concentration and short term mortality from injuries in men and women. $B M{ }^{\gamma}$ 1992;305:277-9. (1 August.)

Muldoon MF, Manuck SB, Matthews KA. Lowering cholester concentrations and mortality: a quantitative review of primary prevention trials. $B M \mathcal{F} 1990 ; 301: 309-14$

EDrToR,-In their long term follow up of adults who participated in the Värmland survey in Sweden, Gunnar Lindberg and colleagues report a significantly higher incidence of suicide and violen deaths in middle aged and elderly men whose cholesterol concentrations were in the lowest quarter of those surveyed. ${ }^{1}$ This difference in violent deaths was limited to the first seven years of follow up. A cause and effect relation is suggested.

Suicide and risk taking behaviours are most commonly found among middle aged or elderly men with psychological depression. ${ }^{23}$ Loss of appetite and weight loss are characteristic of this state or illness, ${ }^{34}$ and loss of over $5 \%$ of body weight is regarded as one of the diagnostic characteristics of acute depressive illness. ${ }^{3}$ Weigh loss is strongly associated with a fall in serum total cholesterol concentration. ${ }^{56}$

Among middle aged men $2 \cdot 5-3 \cdot 2 \%$ are estimated to have an acute depressive illness at any one time, ${ }^{3}$ while others may suffer from reactive depression based on losses and social misfortune. ${ }^{24}$ Thus in the Värmland study a sizeable group of men might be expected to have been depressed at the time of the survey. Most of these would have recently los weight or been losing weight. For many of them their cholesterol concentrations would have fallen, or been falling, into the lowest quartile at that time. They would be at risk of violent death from suicide or risk taking behaviours during the ensuing months or few years. ${ }^{23}$

Lindberg and colleagues found no relation between low cholesterol concentrations and suicide in women. Depressed women are much less likely to commit suicide than are depressed men. ${ }^{23}$ The authors noted no significant interaction between cholesterol concentrations and suicide with age. They do not report the relation between cholestero concentrations and body mass index in the survey, although body mass index was included in the survey.

What the study probably indicates is that men who met violent deaths, commonly from suicide, had been depressed for some time beforehand and because of weight loss, had lower serum cholesterol concentrations.

ALAN J GOBLE

MARIAN C WORCESTER

National Heart Foundation of Australia

Centre for Social and Preventive Research,

PO Box 607, Carlton South,

Melbourne 3053, Australia

1 Lindberg G, Råstam L, Gullberg B, Eklund GA. Low serum cholesterol concentration and short term mortality from injuries in men and women. $B M \mathcal{F}$ 1992;305:277-9. (1 August.) 2 Stengel E. Suicide and attempted suicide. Revised ed. Harmondsworth, Middlesex: Penguin, 1970.

American Psychiatric Association. Diagnostic and statistical manual of mental disorders, third edition, nevised. Washington, DC: American Psychiatric Association, 1987

Seligman MEP. Helplessness: on depression, development and death San Francisco: W H Freeman, 1975.

5 Krombout D. Body weight, diet and serum cholesterol in 871 middle-aged men during 10 years of follow-up (the Zutphen study). Am J Clin Nutr 1983;38:591-8.

6 Tuomilehto J Salonen IT, Nissinen A. Factors associated with changes in serum changes in serum cholesterol during a community-based

7 Lindberg G, Eklund GA, Gullberg B, Råstam L. Serum sialic acid concentration and cardiovascular mortality. $B M$ 1991;302:143-6.

DITOR,- The paper by Gunnar Lindberg and colleagues provides support for a link between low serum cholesterol levels and suicide. ${ }^{1}$ Although the authors comment that the causality of the link is unresolved, we think that several points should be noted.

Lipid was measured as single random serum total cholesterol concentration; allowance is therefore needed for day to day intrapatient variation of up to $11 \%^{2}$ and the influence of seasonal or other factors. It would be desirable to see data on high density lipoprotein and low density lipoprotein cholesterol to put the association in simila terms to those used in ischaemic heart disease. This may also provide evidence for the confounding effect of alcohol misuse, which is shown to increase high density lipoprotein cholesterol. ${ }^{3}$

We propose several other confounding variables: a highly energetic and active lifestyle, while lowering cholesterol, may predispose to fata accidents; ongoing ill health other than cancer can lower total cholesterol concentrations and may give rise to depressive illness and thus increase the risk of suicide.

We emphasise that the findings of this study do not establish a causal relation between suicide and low cholesterol. It is equally possible that people in this Swedish study who were likely to commi suicide may have had low cholesterol levels due to their depressive nature and physical state.

H J MARSHALI D G BEEVER

Department of Medicine,

Dudley Road Hospital

Dudley Road Hospital,
Birmingham B18 7QH

1 Lindberg G, Rástam L, Gullberg B, Eklund GA. Low serum cholesterol concentration and short term mortality from injury in men and women. $B M \mathcal{F}^{7} 1992 ; 305: 277-9$. (1 August.)

2 in men and women. $B M$ Memer PNM. Intra-individual variation of serum cholesterol, triglycerides and high density cholesterol in normal humans. Atherosclerosis 1982;45:259-66.

3 Castelli WP, Doyle JT, Gordon T, Hames CG, Hjortland MC Halley SB, et al. Alcohol and blood lipids. Lancet 1977;i:

AUTHORS' REPLY,-We concluded firmly that although our results supported an association between the risk of suicide and cholesterol concentrations in men, the direction of this relation was not resolved. We were hesitant to speculate too far on this, but several explanations have been brought up in this correspondence.
David Benton and Joyce Fordy suggest that low cholesterol concentration is associated with low mood. Even though their own data provided no support for this in men it is thought provoking, especially in the light of a recent hypothesis about poor suppression of harmful behavioural impulses in subjects with low cholesterol.'

Alan J Goble and Marian C Worcester suggest that we try the possible confounder of loss of appetite in the depressive state, by adjusting for body mass index. The correlation between total cholesterol and body mass index in our cohort as well as in other populations was low $(r=0.11$ in men), and thus it is unlikely that this analysis should provide any new information. As they state, there is a higher correlation between weight change and cholesterol change, but only one recording of these two variables is available in the Varmland study, and thus no correction is possible.

Confounding from a highly energetic and active lifestyle is a different possibility, worth investigating in future studies. The same is true for ill health, which we ruled out as far as possible by excluding subjects included on the registry.

All these explanations are, as far as present knowledge allows us to conclude, equally probable and should if possible be addressed in future studies of the impact of total cholesterol concentration on disease incidence and mortality.

GUNNAR LINDBERG LENNART RåSTAM

BO GULLBERG GUNNAR A EKLUND

Department of Community Health Sciences,

Lund University, Malmö

1 Engelberg H. Low serum cholesterol and suicide. Lancet 1992 339:727-9.

\section{Vaccination against Haemophilus influenzae b disease}

EDrroR,-Keith A V Cartwright states that Haemophilus influenzae $\mathrm{b}$ vaccine may be given concurrently with diphtheria, tetanus, and pertussis vaccine or with measles, mumps, and rubella vaccine into a different limb. ${ }^{1}$ The latest edition of the handbook on immunisation against infectious disease agrees with this and adds that the sites of injection should be recorded. ${ }^{2}$ In the event of any local reaction, confusion may arise as to the responsible vaccine unless it is both clearly recorded in the notes and the child's parents are aware which vaccine has been given in which site. In York Health Authority, to avoid this potential problem, we are currently recommending that $H$ influenzae b vaccine should always be given in the right limb, with the other side being available for other vaccines. Other health authorities may wish to follow suit.

York Health Authority,

C J P SAUNDERS York YO3 7BY

1 Cartwright KAV Vaccination against Haemophilus influenzae disease. BMY 1992;305:485-6. (29 August.)

2 Department of Health. Immunisation against infectious disease. London: HMSO, 1992.

\section{Site of injection for vaccination}

EdrToR,-Colin Payton illustrates the validity of my concern over the misconception of many who administer vaccines that the deltoid area is a superior site for injection.

There are no data comparing vaccine absorption in the muscles of the deltoid region and the anterolateral aspect of the thigh, but there is no valid reason to suspect that any differences exist. 